University of Nebraska - Lincoln

DigitalCommons@University of Nebraska - Lincoln

U.S. Department of Veterans Affairs Staff

Publications

U.S. Department of Veterans Affairs

2012

Do initial responses to drugs predict future use or abuse?

Harriet de Wit

University of Chicago, hdew@uchicago.edu

Tamara J. Phillips

Oregon Health \& Science University, phillipt@ohsu.edu

Follow this and additional works at: https://digitalcommons.unl.edu/veterans

de Wit, Harriet and Phillips, Tamara J., "Do initial responses to drugs predict future use or abuse?" (2012). U.S. Department of Veterans Affairs Staff Publications. 34.

https://digitalcommons.unl.edu/veterans/34

This Article is brought to you for free and open access by the U.S. Department of Veterans Affairs at DigitalCommons@University of Nebraska - Lincoln. It has been accepted for inclusion in U.S. Department of Veterans Affairs Staff Publications by an authorized administrator of DigitalCommons@University of Nebraska - Lincoln. 
Review

\title{
Do initial responses to drugs predict future use or abuse?
}

\author{
Harriet de Wit ${ }^{\mathrm{a}, *}$, Tamara J. Phillips ${ }^{\mathrm{b}}$ \\ a Department of Psychiatry and Behavioral Neuroscience, University of Chicago, 5841 S Maryland Ave, MC3077, Chicago, IL 60637, United States

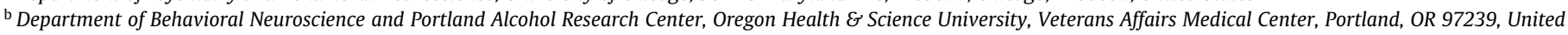 \\ States
}

\section{A R T I C L E I N F O}

\section{Article history:}

Received 28 November 2011

Received in revised form 9 March 2012

Accepted 12 April 2012

\section{Keywords:}

Drug abuse

Initiation

Acute drug effects

Predictors

Risk

Human

Nonhuman

\begin{abstract}
A B S T R A C T
Individuals vary in their initial reactions to drugs of abuse in ways that may contribute to the likelihood of subsequent drug use. In humans, most drugs of abuse produce positive subjective states such as euphoria and feelings of well-being, which may facilitate repeated use. In nonhumans, many drugs initially increase locomotor activity and produce discriminative stimulus effects, both of which have been considered to be models of human stimulant and subjective states. Both humans and nonhumans vary in their sensitivity to early acute drug effects in ways that may predict future use or self-administration, and some of these variations appear to be genetic in origin. However, it is not known exactly how the initial responses to drugs in either humans or nonhumans relate to subsequent use or abuse. In humans, positive effects of drugs facilitate continued use of a drug while negative effects discourage use, and in nonhumans, greater genetic risk for drug intake is predicted by reduced sensitivity to drug aversive effects; but whether these initial responses affect escalation of drug use, and the development of dependence is currently unknown. Although early use of a drug is a necessary step in the progression to abuse and dependence, other variables may be of greater importance in the transition from use to abuse. Alternatively, the same variables that predict initial acute drug effects and early use may significantly contribute to continued use, escalation and dependence. Here we review the existing evidence for relations between initial direct drug effects, early use, and continued use. Ultimately, these relations can only be determined from systematic longitudinal studies with comprehensive assessments from early drug responses to progression of problem drug use. In parallel, additional investigation of initial responses in animal models as predictors of drug use will shed light on the underlying mechanisms.
\end{abstract}

(C) 2012 Elsevier Ltd. All rights reserved.

\section{Contents}

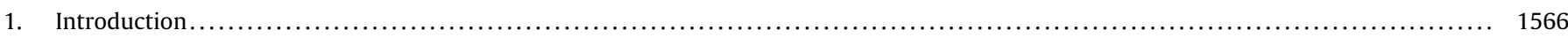

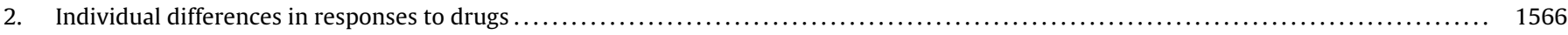

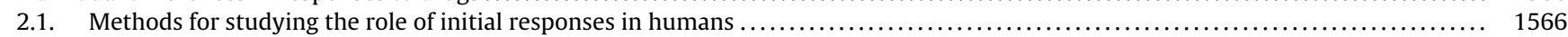

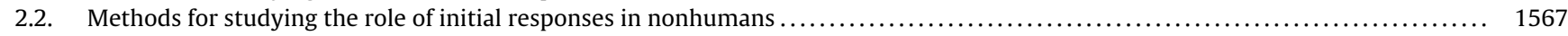

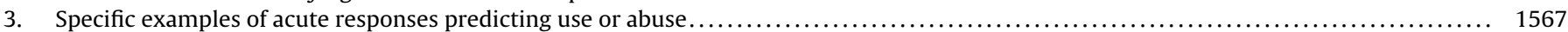

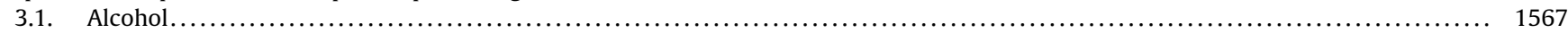

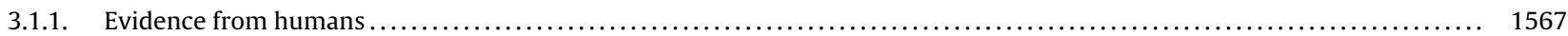

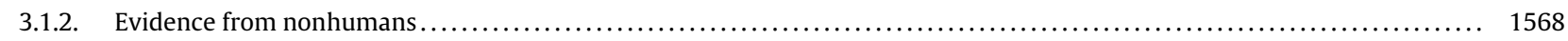

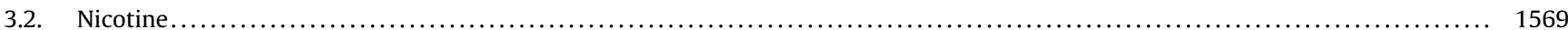

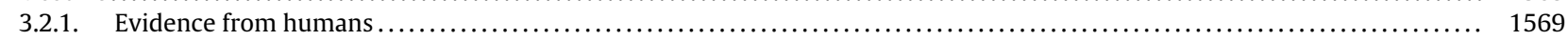

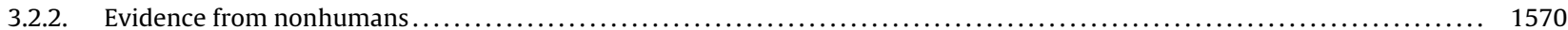

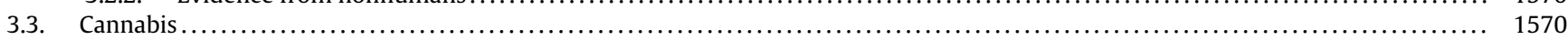

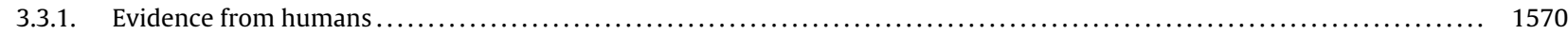

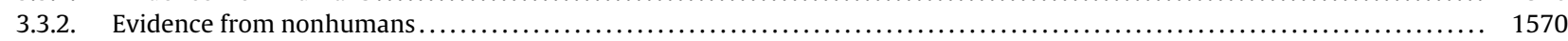

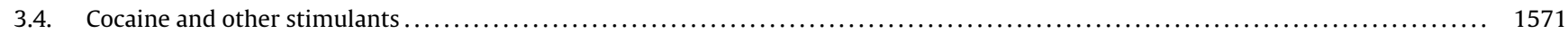

\footnotetext{
* Corresponding author. Tel.: +1 773702 1537; fax: +1 7738347698.

E-mail address: hdew@uchicago.edu (H. de Wit).
} 


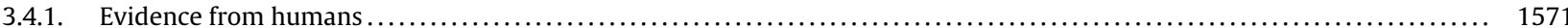

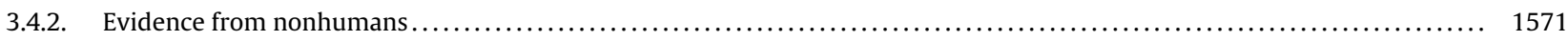

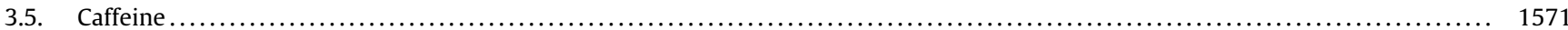

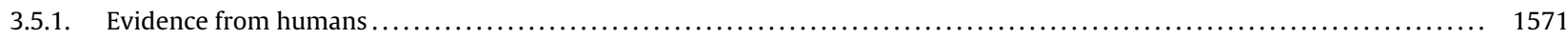

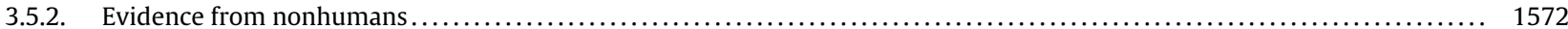

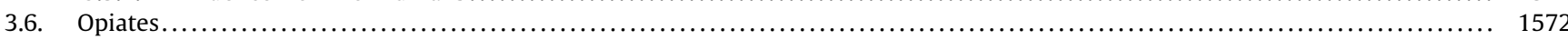

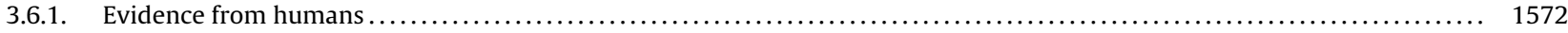

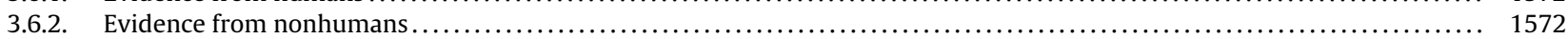

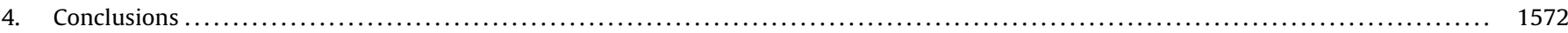

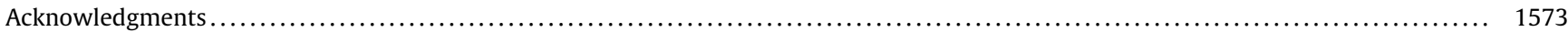

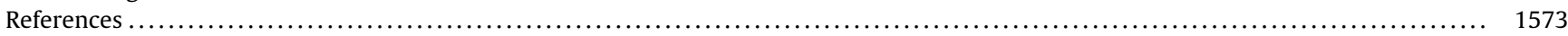

\section{Introduction}

Most drugs of abuse produce subjective feelings of well-being and euphoria in humans, which are thought to contribute to the drug's potential to be used or abused (de Wit and Griffiths, 1991; Fischman and Foltin, 1991). Indeed, drug-induced changes in mood or subjective state have long been the primary indicator of abuse potential used by the Food and Drug Administration (FDA) to assess the likelihood of abuse for new medications (Jasinski, 1991; FDA guidelines in Balster and Bigelow, 2003; Carter and Griffiths, 2009). Drugs that produce euphoria are more likely to be abused than drugs that fail to produce euphoria, and individuals who report experiencing more positive effects from a drug are more likely to use the drug again. However, the extent to which either the quality or magnitude of responses to the first few exposures to a drug are indicators of the individual's likelihood of continued use, or in the longer term to abuse or dependence, remains to be determined. The full clinical manifestation of drug dependence results from dynamic changes that occur only after repeated administration of the drug, including alterations related to learning, tolerance, cognitive function, stress, sensitization and complex neuroadaptations underlying these phenomena (Everitt et al., 2008). Thus, the relationship between early subjective responses and fully developed dependence is at best indirect (Wagner and Anthony, 2002). Yet, there is evidence that an individual's initial responses to drugs may constitute one factor contributing to the risk for future abuse or dependence. This is of particular interest because of the possibility that genetic factors may influence these initial responses, and thus impart vulnerability to future use.

\section{Individual differences in responses to drugs}

Individuals may differ in their responses to drugs on several dimensions, any of which may influence subsequent use. Individuals may differ in how the drug makes them feel (i.e., the subjective self-reported states in humans; discriminative stimulus effects in animals), how it affects physiological processes (e.g., heart rate; body temperature) or how it affects their behavior (e.g., risktaking behavior in humans; locomotor activation or depression in rodents). Further, responses to drugs may vary in magnitude (i.e., greater or lesser sensitivity), the quality of effects (e.g., stimulantlike or sedative-like), the affective valence of the effects (e.g., liking, disliking), and the time course (e.g., onset or duration). These variations in acute drug effects may be genetic or nongenetic in origin. Further, several of these dimensions have been implicated in the etiology of drug abuse or dependence. For example, Conrod et al. (2001) suggest that the amount of increase in heart rate after alcohol is a positive indicator of risk for abuse, and Schuckit (1987) and others have suggested that low level of intoxication-like response to alcohol is a risk factor for future alcohol dependence. Evidence for the causal role of these potential predictors is difficult to obtain in humans. In nonhumans, there is also a literature examining the relation between initial responses to drugs and future drug self-administration (see below). Advantages of the animal models include the degree of control over the animals' drug use history, and the capacity to manipulate genetic variables. Although a comprehensive review of the nonhuman mammalian literature is beyond the scope of the present analysis, we note some interesting similarities between humans and nonhumans. It is also important to mention that a potential source of variability affecting both initial responses to drugs and progression to use is variation in the pharmacokinetic properties of a drug. For example, there is genetic variation in the rate at which certain drugs are metabolized, which may affect sensitivity to drug effects and either increase or decrease their risk for using the drug (Edenberg, 2007; Ho and Tyndale, 2007). The most common example of this factor is in the flushing response to alcohol, which decreases risk for developing alcoholism (see below).

\subsection{Methods for studying the role of initial responses in humans}

Information about the relationship between sensitivity to initial drug effects and subsequent use in humans can be obtained from several sources, including retrospective studies with established drug users, longitudinal studies with early drug users, and laboratory-based studies involving drug choice. In retrospective studies, drug abusers are asked to recall their early drug use experiences (e.g., Haertzen et al., 1983). For some drug classes, these retrospective studies provide the only available source of information (e.g., opiate drugs in opiate abusers). However, retrospective studies are limited by their reliance on memory and highly selective bias in respondents, who are usually drug users with many years of drug experience. In prospective studies, initial responses to drugs are assessed in young early or non-users, and then their recreational use is followed over months or years (e.g., studies of early cigarette smokers (Chen et al., 2003; described below)). These studies are especially valuable because they provide a measure of initial drug response, not biased by memory. However, they are expensive and time-consuming, and are not possible for certain drug classes (e.g., illicit opiates). A further limitation of both retrospective and longitudinal studies is that initial drug effects are experienced under naturalistic conditions where expectancies, other concurrent drug use, and context can influence the apparent drug effect. In contrast, in human laboratory studies, participants receive controlled doses of drugs and are then allowed to consume and regulate their intake of the drug (Chutuape and de Wit, 1994; de Wit, 1998). These studies often document the participants' first experience with the drug, unconfounded by expectancies or contextual factors. Participants who report experiencing positive subjective drug effects (e.g., liking or euphoria) typically choose to consume the drug when given the opportunity. This concordance provides support for the idea that greater positive acute effects predict repeated use of the drug within the laboratory setting, and perhaps outside the laboratory as well. The measures of subjective drug effects are sensitive and 
reliable. Yet, in the context of opiate drugs, McAuliffe (1975) noted that subjective drug experiences are sometimes difficult to define, and subjects' ratings of positive effects such as 'euphoria', 'intoxication', 'high' and 'liking' of the drug, may not be readily distinguishable from their ratings of apparently negative effects such as 'nausea', 'sick', 'heavy'. Further, especially in the context of initially unpleasant drugs, users may 'learn to get high', and adapt to unpleasant side effects of the drug with repeated use. Thus, initially unpleasant subjective responses to certain drugs may become positive after relatively few uses.

\subsection{Methods for studying the role of initial responses in nonhumans}

Several experimental approaches have been taken to study the relationship between initial drug effects and use in nonhumans. Individual variation in sensitivity to initial drug effects (e.g., locomotor behavior, sedative effects) can be examined in relation to likelihood of initiating drug intake or amount consumed (e.g., Piazza et al., 1989; Pierre and Vezina, 1997). These studies provide some evidence that initial drug responses predict future use. However, many of the existing studies used genetically heterogeneous populations (parallel to unselected populations of humans), making it difficult to discern the specific roles of genetic and nongenetic factors in sensitivity. Moreover, these studies sometimes entail some initial drug exposure to identify a predictor trait, and this exposure itself could affect the subsequent intake measure. An alternative approach to studying the relation between initial drug responses and drug intake, which avoids this problem, is to utilize genetically defined types of animals to examine genetic correlations between acute drug responses and drug self-administration (e.g., Kamens et al., 2005). For example, this approach can be taken using panels of inbred mouse and rat strains, selectively bred lines of rodents and animals in which single genes have been manipulated. These studies may reveal common genetic factors that influence both initial sensitivity and drug intake.

\section{Specific examples of acute responses predicting use or abuse}

The extent to which sensitivity to acute drug effects in humans predicts the trajectory of drug use outside the laboratory remains to be determined. Clearly, a multitude of other factors contribute to the etiology of drug abuse and dependence, including non-drugrelated factors such as stress and impulsivity, and drug factors that only come into play after repeated ingestion of the drug in a specific context such as conditioning, tolerance and sensitization (Everitt et al., 2008). Recognizing that the initial reaction to a drug is but one of many factors that contribute to compulsive drug use, we evaluate evidence in humans and nonhumans that the initial drug effects contribute to subsequent regular use of alcohol, nicotine, cannabis, cocaine, caffeine and opiates. These drugs are included because they are among the most commonly used or abuse drugs for which pertinent data are available. Other drug classes, such as hallucinogens, benzodiazepines, barbiturates, inhalants and dissociative anesthetics will not be discussed because there is not enough information available.

We review evidence from both humans and nonhuman models. The concordance from human to nonhuman findings depends on the sensitivity and validity of the nonhuman models used. As noted in several recent reviews examining the consilience between rodent models and human measures of sensitivity to alcohol or nicotine (Crabbe et al., 2010; O'Dell and Khroyan, 2009; Stephens et al., 2011), there is a need for more refined measures in animals to match the measures used with humans. Nevertheless, we review the existing evidence from the nonhuman models to address the specific question, i.e., do initial responses to drugs predict future use? This information will provide a context for studying variability in early drug responses, related to both genetic and non-genetic factors, in relation to continued use (e.g., Haberstick et al., 2011; Lott et al., 2005).

\subsection{Alcohol}

\subsubsection{Evidence from humans}

One well-documented source of variation in acute responses to alcohol stems from metabolic differences related to enzymes involved in the degradation of alcohol (Edenberg, 2007). Certain individuals, notably those of East Asian descent, experience an aversive facial flushing response after consuming alcohol, a response that can also include nausea, discomfort and tachycardia. The response is due to accumulation of the metabolite acetaldehyde, which can occur either from more rapid oxidation of alcohol by alcohol dehydrogenase (ADH) or from slower oxidation of acetaldehyde by aldehyde dehydrogenase (ALDH). Several genetic variants have been identified that affect both of these enzymes, and individuals affected by the flushing response have a markedly lower probability of developing alcoholism, presumably because of the aversive effects they experience after consuming alcohol (Edenberg, 2007; Whitfield, 2002).

There is also well-described individual variation in the pharmacodynamic profile of alcohol. Most of the studies that have examined acute responses to alcohol as predictors of future alcohol use focus on young adults with a family history of alcoholism, but who have not yet themselves developed the disorder. Alcohol abuse and dependence are highly heritable, such that children of alcoholics are 4-5 times more likely to become alcoholic themselves (Schuckit, 1985a). The processes that mediate this risk are not understood, but one approach has been to compare responses to an acute dose of alcohol in individuals with or without a family history of alcoholism, while they are young and presumably at risk but not yet dependent. Schuckit and his colleagues have conducted an elegant series of studies addressing this question, demonstrating that sons of alcoholics exhibit a distinctive "low level of response" to certain effects of alcohol (Schuckit, 1984a,b, 1994). They found that sons of alcoholic fathers report less subjective intoxication and body sway after a moderate dose of alcohol than men without alcoholic relatives. These at-risk individuals also exhibit less alcohol-induced body sway (Schuckit, 1985b, 1988), smaller alcohol-induced alterations in cortisol, prolactin, and ACTH levels, less intense changes in the P300 component of the eventrelated potential and differential EEG effects (Ehlers and Schuckit, 1990; Schuckit, 1988; Schuckit et al., 1987a,b; Schuckit and Gold, 1988). The reduced level of response also occurs in daughters whose fathers have a history of alcohol dependence (Eng et al., 2005). From these data, Schuckit and colleagues proposed a low-level response theory. Individuals who are insensitive to these effects of alcohol are postulated to be more susceptible to future alcohol use, and ultimately abuse, because they are unable to gauge their own level of intoxication, and because they need greater amounts of alcohol to achieve the desired effects. In support of this idea, Schuckit (1994) conducted a 10 -year follow-up study showing that a low response to alcohol predicted a four-fold increase in likelihood of developing future Alcohol Dependence (APA, 1994). These studies indicate that lesser responses to alcohol, including certain subjective and physiological responses, represent a risk factor not only for alcohol use, but also for future alcohol abuse or dependence. However, as noted next, alternatives to this theory have also been proposed.

An alternative to Schuckit's low-level response theory was proposed by Newlin and Thomson (1990), and recently re-examined by Newlin and Renton (2010). These authors cite 36 studies in 
which high-risk family history positive individuals demonstrated higher levels of early alcohol response compared to low-risk groups, on measures ranging from subjective reports of alcohol effects (e.g., stimulation, intoxication), to physiological effects (e.g., heart rate and cortisol) and behavioral measures (e.g., memory impairment). The authors noted that the studies that reported greater effects typically measured responses very soon after drug administration (sooner than most of the Schuckit studies), and thus proposed a differentiator model, that high-risk individuals have greater stimulant-like effects from alcohol during the ascending limb of the breath alcohol curve and less sedative-like effects during the descending limb. Thus, the models are consistent, but the differentiator model takes into account the biphasic nature of alcohol's effects. Hendler et al. (2011) provide an in-depth review of the variations in the stimulant and sedative effects of alcohol across individuals, and how these may be related to future alcohol consumption. There is consensus that relative predictive value of these proposals (low level response vs. differentiator model) will only be resolved with further, in-depth longitudinal studies.

Taken together, these studies with alcohol provide some support for the idea that variation in initial responses to alcohol can predict levels of future alcohol use. Yet, the findings are complex and sometimes conflicting. Acute alcohol effects that are clearly unpleasant (e.g., flushing) appear to discourage drinking. Either greater stimulant effects or lesser sedative effects appear to predict escalation of drinking. Notably, however, alcohol challenge studies in the United States typically include participants 21 years of age and older, whose responses may already be influenced by prior experience. Assessing responses to alcohol at an earlier age would provide more accurate measure of biological response and potential risk. Indeed, to the extent that early age of onset of drinking is a predictor of future abuse (Grant, 1998; Moss et al., 2007), the first experiences of greatest importance may occur much earlier than 21 years of age. It is not even known whether acute response to alcohol is systematically related to age during the early, vulnerable ages. Another limitation to the human alcohol challenge studies is that most studies have tested healthy, young, usually Caucasian, volunteers without psychiatric or other substance disorders. Considering the prevalence of psychiatric comorbidity between alcohol dependence and other psychiatric conditions, it would be of particular interest to examine early responses to alcohol among individuals with psychiatric disorders or dysregulated HPA function. It is also likely that there are multiple trajectories to alcohol dependence such as the type 1 higher functioning, environmentally influenced alcoholism, and the type 2 male-predominant familial, severe alcoholism characterized by onset before age 25 (Cloninger et al., 1981). A recent large-scale study suggested that there are as many as five different subtypes, each with a distinctive etiology and trajectory (Moss et al., 2007). Initial reactions to alcohol may play a different role in these subtypes (e.g., Gordh et al., 2011). Future research on the relation between initial alcohol responses and alcohol use disorders may help to refine these subtypes and their biological mechanisms.

\subsubsection{Evidence from nonhumans}

In nonhumans, metabolic factors have also been considered. An Aldh type 2 knockout mouse that has high acetaldehyde levels in blood, brain and liver after alcohol exposure (Isse et al., 2005), exhibits a reduced preference for alcohol (Isse et al., 2002). Further, alcohol has differential effects on Aldh type 2 gene expression in different strains of mice, that correspond with their differences in alcohol preference, indicating a genetic correlation between these traits. A more modest correlation was found between Adh type 1 gene expression and alcohol preference in these mouse strains (Tagliabracci and Singh, 1996). However, the role of these enzymes in the brain appears to be more complicated, as there is also evidence that these alcohol metabolizing enzymes in the brain may play a positive role in the reinforcing effects of alcohol (Karahanian et al., 2011). These authors suggest that alcohol serves as a prodrug for acetaldehyde, and that acetaldehyde serves as the active reinforcing drug. This builds on an older literature suggesting that acetaldehyde plays a role in alcohol self-administration (e.g., Amit et al., 1977). In addition, metabolites of alcohol, such as acetate, may be another source of variation in sensitivity to aversive effects of alcohol that influences alcohol consumption (Maxwell et al., 2010).

The animal alcohol literature provides mixed support for the idea that alcohol sensitivity is associated with level of alcohol use. As with the human findings just described, sensitivity in animals is not a singular concept, and has been measured in many ways. For example, one commonly used measure of alcohol sensitivity in animals is locomotor activity. Alcohol can either increase or decrease locomotor activity, depending upon the dose of alcohol and the time after alcohol administration at which behavior is measured. Mice bred to have a greater locomotor stimulant response to alcohol early after administration (Crabbe et al., 1987; Phillips et al., 2002) consume more alcohol (Risinger et al., 1994). To the extent that locomotor activity represents stimulant-like positive effects, this is consistent with the idea that greater sensitivity to positive stimulant effects of alcohol predicts more alcohol use. Also, consistent with both the differentiator and low level of response models, the higher alcohol consuming line of mice are less sensitive to the sedative-hypnotic and some ataxic effects of alcohol (Shen et al., 1996; Phillips et al., 2002; but see Boehm et al., 2000). In addition, using data from several laboratories collected in a panel of inbred rat strains, a correlational approach and subsequent factor analysis offered some support for a relationship between higher alcohol intake and lower initial sensitivity to sedative-intoxicating effects of alcohol (Spuhler and Deitrich, 1984). These findings, taken together with data from inbred mouse strains, examining sensitivity-intake relationships (Ozburn et al., 2010; Crabbe et al., 2010) provide inconclusive evidence for the relation between initial stimulant effects and subsequent alcohol consumption.

Lines of mice and rats have also been bred for their large differences in alcohol consumption, but the findings have been mixed, with regard to their initial sensitivity to alcohol. The low level of response relationship with high intake has received some, but not perfect, support for some sedative and ataxic effects of alcohol (Colombo et al., 2000; Crabbe et al., 2010; Files et al., 1996; Kurtz et al., 1996; Lumeng et al., 1982; Phillips and Crabbe, 1991; Schechter, 1992). Also, a relationship of a greater stimulant response with higher alcohol drinking has sometimes been supported (Agabio et al., 2001; Krimmer, 1992; Krimmer and Schechter, 1992; Quintanilla, 1999; Rodd et al., 2004; Waller et al., 1986), but in other cases has not (Grahame et al., 2000; Paivarinta and Korpi, 1993; Phillips et al., 2005, 1995). Some of the disparity is likely due to the genetic heterogeneity of alcohol drinking, something that must be considered in outcomes from both humans and nonhumans. For example, gene-specific research has identified mechanisms that could underlie a relationship between alcohol sensitivity and consumption (e.g., Hodge et al., 1999; Kim et al., 2011; Naassila et al., 2002; Thiele et al., 2000). However, correspondence of sensitivity with consumption, not surprisingly, has not been found for all genetic manipulations that have been examined (Crabbe et al., 2006).

In rodent studies, conditioned aversive effects of alcohol assessed soon after administration are negatively correlated with consumption. Lines of rats and mice that were bred for higher levels of alcohol consumption also exhibit reduced sensitivity to the conditioned aversive effects of alcohol (Chester et al., 2003; Froehlich et al., 1988; Quintanilla et al., 2001), and conversely, animals bred for greater conditioned aversion consumed less alcohol 
(Phillips et al., 2005). Similar results have been found in pairs, panels and crosses of inbred strains (Broadbent et al., 2002; Horowitz and Whitney, 1975; Ozburn et al., 2010; Risinger and Cunningham, 1992; however, see Cailhol and Mormede, 2002; Risinger and Cunningham, 1998). In general, although exceptions can be found in the literature, the data suggest that there is a genetic relationship between these traits, and that sensitivity to the aversive effects of alcohol serves as a protective factor against excessive alcohol intake. In humans, the initial aversive effect of alcohol has not been systematically studied as a predictor of future use, except in the context of the flushing response in Asians.

In nonhumans, information about the interoceptive effects of alcohol, or how alcohol makes animals "feel", is obtained using drug discrimination methods. In these studies, the animal indicates whether an ingested or injected solution "feels" (or tastes) like alcohol or not, usually by pressing an alcohol-associated or non-alcohol-associated lever. The findings from these studies examining the quality and magnitude of interoceptive effects of alcohol in relation to the propensity to self-administer alcohol have been mixed (Gordon et al., 1993; Krimmer, 1992; Krimmer and Schechter, 1992; McMillan and Li, 1999, 2001; McMillan et al., 1999; York, 1981). However, it was recently shown that chronic exposure to the stress hormone corticosterone blunted the ability of rats to identify alcohol (Besheer et al., 2012). This is consistent with the idea that chronic stress may reduce the subjective effects of alcohol in humans, leading an individual to consume more alcohol to achieve the desired effect.

\subsection{Nicotine}

\subsubsection{Evidence from humans}

Nicotine is a particularly interesting and paradoxical case for examining the idea that initial, acute responses to drugs predict progression to repeated use. Nicotine (or tobacco) is unique among other drugs of abuse in that its initial subjective effects are typically not pleasant, and indeed often include unpleasant experiences such as nausea and dizziness. As a result, it is often thought that early use of tobacco is determined more by environmental influences (e.g., peer pressure) than by pleasant pharmacological effects. Eissenberg and Balster (2000) reviewed the literature on early responses to tobacco in relation to risk for regular smoking. Their review included both retrospective studies assessing memories of early responses among individuals who have tried smoking, as well as longitudinal studies assessing early responses to smoking among pre-adolescents and adolescents. There are several more recent longitudinal studies, and there is also epidemiological evidence relating cigarette smoking to variations in enzymes involved in the metabolism of nicotine.

Several retrospective studies have examined participants' recollections of their initial responses to smoking, as possible predictors of progression. Haertzen et al. (1983) conducted an early retrospective study with opiate abusers who were asked to recall their early experiences with nicotine and other drugs. Whereas they reported pleasurable initial responses to heroin and cocaine which, they claimed, influenced subsequent use, they remembered experiencing mainly unpleasant initial effects from tobacco, and that these effects were unrelated to their subsequent smoking. In their review of initial response as predictor of smoking, Eissenberg and Balster (2000) found mixed results: in some studies, fewer dysphoric effects from initial cigarettes predicted smoking, whereas in other studies more positive effects predicted future smoking. More recently, DiFranza et al. (2004) interviewed 237 seventh graders who had ever inhaled tobacco smoke, regarding their initial sensitivity to effects of nicotine. Relaxation was the strongest predictor of progression to subsequent smoking, but surprisingly and counter-intuitively, nausea, or dizziness also independently predicted progression. Similarly, Chen et al. (2003) surveyed 610 10 th grade students who had ever tried smoking. After controlling for age and gender, pleasurable cigarette smell, pleasurable buzz/rush, relaxation and dizziness predicted continued smoking. The finding that pleasant cigarette smell was a predictor is interesting in light of preclinical evidence that nicotine may enhance the value of environmental stimuli that have some motivational value because of their association with primary rewards (Caggiula et al., 2009; Chaudhri et al., 2006). Alternatively, it is possible that cigarette smell was pleasant because of previous associations with smoking (e.g., parents who smoked). Whether these remembered initial responses to smoking were accurate, and whether they were causally related to progression, cannot be determined from these retrospective studies.

Several prospective studies have examined the relation between initial sensations and later dependence. DiFranza et al. (2007) studied 217 sixth graders who had ever inhaled tobacco smoke, and followed them for 4 years. They found that feelings of relaxation after initial smoking predicted nicotine dependence, or "loss of autonomy over smoking" and dependence (WHO, 1992) 4 years later. Other predictors were familiarity with popular cigarette advertisements (e.g., Joe Camel), novelty seeking and depressed mood. Kandel et al. (2007) conducted a 2-year longitudinal study with 353 6th to 10th graders who had tried a cigarette within the year before the study or during the study. About $25 \%$ of the sample developed Nicotine Dependence (APA, 1994) over a 2-year period, and pleasant initial sensitivity to tobacco smoke was among the best predictors of developing dependence. These authors took care to obtain ratings of pleasantness and unpleasantness with regard to sensations such as dizzy, rush, and buzz, and concluded that sensations that were regarded as pleasant were most predictive. Several other studies have reported similar results (Audrain-McGovern et al., 2007; Hu et al., 2006). More recently, Buchmann et al. (2011) followed a cohort of German adolescents who had ever tried smoking, from age 15 until 22, to identify determinants of progression. They found that earlier age of smoking was associated with more pleasurable sensations from the first cigarette and, although both predicted progression to regular smoking, the age of smoking initiation was the more robust predictor of progression to dependence. The question of whether the subjective or behavioral effects of acute nicotine, or other drugs, vary with age, especially at younger ages, is of critical importance and may explain differences in vulnerability. Ethical concerns about administering drugs to children and adolescents make it unlikely that these important studies will be done. Taken together, however, the prospective studies that have been conducted add to the evidence that initial responses to nicotine contribute to the likelihood of escalation from use to dependence.

Perkins and colleagues have studied subjective responses to acute nicotine in relation to consumption in controlled studies in healthy volunteers (Perkins et al., 2001, 2000, 2008). In one study (Perkins et al., 2001), nonsmokers sampled a nicotine nasal spray, and then had the opportunity to ingest it again. Subjects who reported more positive effects from the spray were more likely to take it again, whereas subjects who experienced negative effects were less likely to take it again. In another study (Perkins et al., 2008), they examined subjects' responses to intranasal nicotine in relation to retrospective reports of early smoking experiences. Adult nonsmokers who had smoked only 1-10 times in their lifetime and remembered feeling dizzy and buzzed from their first cigarette also reported these same effects after receiving nicotine in a nasal spray. They described the effects as unpleasant, which may have contributed to their non-continuation of smoking.

As is the case for alcohol, pharmacokinetic factors may influence rates of smoking, and perhaps early responses to smoking (AudrainMcGovern et al., 2007; Ho and Tyndale, 2007). The metabolic 
inactivation of nicotine is controlled by genes such as CYP2A6 that encodes a hepatic enzyme that affects most of the metabolism of nicotine to cotinine (Benowitz and Jacob, 1994). Some studies have reported that variations in this gene predict nicotine dependence: slower metabolizers, who have genetic variants associated with less than half of the activity of normal metabolizers, smoke fewer cigarettes and are less likely to be current smokers (Malaiyandi et al., 2006). However, this genetic relationship has not always been found (Carter et al., 2004). Whether metabolic factors play a role during early smoking experiences remains to be determined. Audrain-McGovern et al. (2007) examined the role of pharmacokinetic variation in early onset of smoking, in adolescents from grades 9 to 12 . Normal metabolizers progressed to nicotine dependence at a faster rate than slow metabolizers, and these increases in nicotine dependence leveled off more slowly compared with slower metabolizers. However, they found that initial subjective experiences from smoking were not related to the genotypes, nor were they predictive of nicotine dependence.

Thus, the studies with early responses to nicotine provide mixed evidence for the relation between early acute response and smoking progression. Some studies found that initial feelings of relaxation or pleasurable buzz predicted progression, whereas others found that dizziness and even nausea predicted future smoking. Yet other studies found that early responses that were unpleasant decreased the likelihood of progression. These highly variable findings suggest that early positive subjective responses to nicotine may play a minor role in the development of smoking, and that perhaps magnitude of any subjective response (positive or negative) may be predictive. Alternatively, other factors related to context, learning and neurobiological adaptations may be more important for this drug.

\subsubsection{Evidence from nonhumans}

In animals, nicotine also has competing positive and aversive effects. Nicotine self-administration in animals has typically been studied using intravenous (IV) methods, and dose-response curves for IV self-administration have typically been inverted U-shaped, reflecting lower dose positive effects through higher dose aversive properties. Nicotine self-administration has been demonstrated in several species (e.g., mice-Stolerman et al., 1999; rat-Corrigall and Coen, 1989; Brower et al., 2002; dog-Risner and Goldberg, 1983; nonhuman primate-Sannerud et al., 1994). However, few studies have examined the relationship between initial sensitivity to nicotine and nicotine intake. Recent reviews (Changeux, 2010; Tuesta et al., 2011) nicely detail current knowledge about the involvement of specific nicotinic receptor subtypes, signaling mechanisms and brain locations in nicotine, as well as other drug, self-administration behavior, but does not touch on the topic of initial sensitivity. However, there are genetic differences in sensitivity to behavioral effects of nicotine (Bergstrom et al., 2003; Boyle and Gill, 2009; Gill and Boyle, 2005; Marks et al., 1989; Overstreet, 1995; Tritto et al., 2004, 2002), which may affect selfadministration. Using inbred mouse strains varying in sensitivity to the first dose of nicotine, Robinson et al. (1996) examined whether initial sensitivity corresponded with oral self-selection of nicotine, when the animals were offered the choice of a nicotine-containing solution vs. water or saccharin water. They found a strong negative genetic correlation between nicotine intake and sensitivity to nicotine-induced seizures, suggesting that sensitivity to an apparently aversive effect of nicotine may limit intake. This relationship deserves further more careful study in animal models.

As in the studies with humans, pharmacokinetic factors may also affect nicotine self-administration in mice. Mice with greater CYP2A5 protein levels (homologous with human CYP2A6 protein), suggestive of an increased rate of nicotine metabolism, showed increased nicotine self-administration (Siu et al., 2006). In addition, rats of the Lewis strain have been found to self-administer more nicotine than rats of the Fischer 344 strain, and they also appear to have a more rapid nicotine clearance curve, and perhaps higher initial peak levels of nicotine (Sziraki et al., 2001).

\subsection{Cannabis}

\subsubsection{Evidence from humans}

Both retrospective and prospective studies have examined the relationship between initial responses to cannabis and subsequent use of marijuana. Davidson and Schenk (1994) queried 197 college students about memories of their initial experiences with marijuana, using a questionnaire describing both positive and negative effects. Respondents who experienced more positive effects from the drug the first time had a shorter latency to their second use as well as higher lifetime use. Although only a few respondents reported negative effects from the drug, these negative ratings did not predict use. Le Strat et al. (2009) conducted a retrospective analysis of 1472 young cannabis users in New Zealand and France to investigate the positive and negative effects of cannabis at first use in relation to cannabis dependence at age 18-21. Participants rated the number of positive experiences from the cannabis at initial use, from 1 to 5 positive responses (e.g., feeling high or happy). The study found that the odds ratio of developing cannabis dependence among respondents who reported 5 positive effects was 28 times that of becoming dependent with no initial positive effects, although the categorical classification of ratings limits the conclusions that can be drawn. Fergusson et al. (2003) conducted a longitudinal study of 198 respondents who had used cannabis before age 16, again using the ratings of $1-5$ positive experiences. Participants who reported 5 positive responses to cannabis at initial use had an odds ratio of 28.5 for becoming dependent 4 years later, compared to respondents who reported no positive effects. As in the Davidson and Schenk (1994) study, negative experiences were unrelated to future use. Taken together, these studies suggest that positive subjective responses to initial marijuana experiences are predictive of future use. It should be noted, however, that many factors influence subjective responses to drugs, especially marijuana, including expectancies (Kirk et al., 1998), prior drug use and personality (Chait and Perry, 1992). Thus, although early ratings of liking marijuana appear to predict future use, the extent to which this is based on the pharmacological response is not known. This would only be answerable with controlled studies in which the drug could be administered for the first time under double blind conditions, which is unlikely to occur. This problem with expectances also applies to the first use of other classes of drugs in a naturalistic situation, where users almost always have expectancies regarding the drug's identity and its effects.

\subsubsection{Evidence from nonhumans}

The natural cannabinoid, delta(9)-tetrahydrocannabinol (THC), and synthetic and endogenous cannabinoid receptor agonists such as, WIN 55212-2 and anandamide, are self-administered by animals (monkeys-Justinova et al., 2008; Tanda and Goldberg, 2003; Tanda et al., 2000; rats-Fattore et al., 2001; Lecca et al., 2006; mice-Mendizabal et al., 2006). However, some have argued that cannabinoids are atypical in preclinical animal models with regard to their profiles as drugs of abuse, because the experimental conditions under which motivational and reinforcing effects are displayed are more restricted than for other drugs of abuse (Panagis et al., 2008). Stimulant and depressant responses to acute cannabinoids have been recorded (Bass et al., 2002; Darmani, 2001; Meschler et al., 2000; Varvel et al., 2007; Wiley et al., 2008), as have aversive effects (McGregor et al., 1996; Murray and Bevins, 2010). Further, the role of endogenous endocannabinoids and their receptors more generally in drug reinforcement and other 
addiction-related behaviors (Serrano and Parsons, 2011), and in stress associated responses (Dubreucq et al., 2012; Riebe and Wotjak, 2011), has more recently received considerable attention. However, the question of whether initial sensitivity to cannabinoids predicts level of cannabinoid intake does not appear to have been addressed in animal models of cannabinoid use. This is perhaps partly because self-administration of cannabinoids has been more difficult to reliably establish in animal models compared to self-administration of most other addictive drugs.

\subsection{Cocaine and other stimulants}

\subsubsection{Evidence from humans}

A few retrospective studies have examined initial response to cocaine or other stimulants as a predictor of future use. In one early study (Haertzen et al., 1983) opiate abusers claimed that initially positive responses to cocaine predicted their later use of the drug. Davidson et al. (1993) interviewed 44 college students who reported having used cocaine and found that positive responses to the drug on initial use predicted a shorter latency to the second use. Negative effects did not predict future use. More recently, Lambert et al. (2006) conducted a study with 202 adults who had tried cocaine at least once between ages 16 and 40. Participants who reported 'liking' and 'wanting' the drug upon initial exposure to cocaine were more likely to develop cocaine dependence and life-time cocaine abuse.

Many laboratory-based studies have examined subjective responses to stimulant drugs such as amphetamine and methylphenidate in healthy volunteers, in relation to consumption or choice (Chait, 1993; de Wit et al., 1986; Holdstock and de Wit, 2001; Johanson and Uhlenhuth, 1980; Kollins et al., 2001; Lott et al., 2005; Rush et al., 2001; Volkow et al., 1999). Healthy young adults vary in their ratings of arousal, liking and anxiety after low doses of amphetamine. These studies consistently show that pleasurable, stimulant-like subjective effects are directly related to consumption of the drug, within the experimental context. In the studies with amphetamine, most participants experience positive mood effects from amphetamine during their first experiences with them, but a small minority experience unpleasant effects such as anxiety. The mood effects of the drug clearly predict whether subjects will choose to take the drug again when they are given the opportunity, on subsequent study sessions. These studies provide strong support for the idea that pleasurable initial responses are related to subsequent drug-taking, albeit in the limited context and abbreviated time frame of a laboratory research study. These acute drug challenge studies may help to identify risk factors predicting future use, including genetic factors (Hart et al., 2012; Lott et al., 2005), personality and psychiatric symptoms (de Wit and Bodker, 1994; de Wit et al., 1987), expectancies (Mitchell et al., 1996) and brain dopamine receptor density (Volkow et al., 1999). The studies show systematic relations between acute drug responses and drug choice in the laboratory.

\subsubsection{Evidence from nonhumans}

In rats, using genetically heterogeneous groups of animals, locomotor response to an acute dose of a psychostimulant may predict consumption of the drug. For amphetamine, greater acute sensitivity to locomotor effects of the drug was associated with higher levels of self-administration (Deminiere et al., 1989; Piazza et al., 1989). This relationship has also been found for cocaine in some, but not all, studies (Mandt et al., 2012, 2008; Mantsch et al., 2001). When approaches have been used that directly investigate potential genetic relationships between sensitivity and intake, evidence has also been mixed. In a panel of inbred mouse strains, postprandial drinking of cocaine and sensitivity to the stimulant effects of cocaine were not strongly related (Seale and Carney, 1991).
However, in rat lines selectively bred for high vs. low locomotor activity in a novel environment, the high activity line rats exhibited a higher propensity to self-administer cocaine (Cummings et al., 2011; Davis et al., 2008) and greater sensitivity to quinpirole (Flagel et al., 2010), a dopamine D2/D3 receptor agonist, which would be thought to partly mimic the effects of cocaine. Unfortunately, to the best of our knowledge, drug sensitivity has not been fully characterized in these lines, although one study showed no difference between the lines in activation to an initial treatment with a $15 \mathrm{mg} / \mathrm{kg}$ dose of cocaine (Garcia-Fuster et al., 2010). A mouse line selectively bred for higher oral intake of methamphetamine (Shabani et al., 2011; Wheeler et al., 2009) that also exhibits greater operant methamphetamine self-administration (Shabani et al., 2012a) exhibits greater acute locomotor activation to methamphetamine (Shabani et al., 2011). However, mice bred for extreme sensitivity to the stimulant effects of methamphetamine voluntarily consume less methamphetamine compared to the oppositely selected low stimulation line (Kamens et al., 2005). The authors suggest two interpretations. First, the mice bred for high stimulation may require less MA to experience rewarding effects and thus, may choose to consume less MA compared to the mice bred for low stimulation. Alternatively, extreme sensitivity to the stimulant effect could be aversive, and thus, avidity for methamphetamine is reduced. The positive association of methamphetamine intake and stimulation in the lines bred for high and low MA drinking was seen only at a higher $4 \mathrm{mg} / \mathrm{kg}$ dose, whereas the stimulation selected lines were bred based on their response to $2 \mathrm{mg} / \mathrm{kg}$ methamphetamine. It is possible that the use of the lower dose resulted in a more profound sensitivity, as one would expect to identify more sensitive animals with this low dose, than with a higher dose.

In addition to the association of sensitivity to stimulant effects with intake, aversive effects of methamphetamine have been studied. Mice bred for low drinking of methamphetamine solutions showed profound conditioned aversion induced by a single treatment with methamphetamine that was not seen in the high drinking line mice, even after multiple treatments (Shabani et al., 2012b; Wheeler et al., 2009). These results are similar to those for alcohol, and suggest that high sensitivity to the aversive effects of methamphetamine protects against high levels of intake.

Another source of information about initial responses to drugs and drug-taking in animal models comes from studies of discriminative stimulus effects. For example, rats that were more sensitive to the activating effects of amphetamine were also more sensitive to its discriminative stimulus effects (Bevins et al., 1997). In a study in non-human primates investigating cocaine self-administration and drug discrimination, at least one dose supported only self-administration without serving as a discriminative stimulus. This suggests that cocaine reinforcement can occur in the absence of a cocaine-like discriminative stimulus effect (Martelle and Nader, 2009). However, once a drug has been established as a discriminative stimulus, it can substantially increase subsequent self-administration (Panlilio et al., 1996). Thus, sensitivity to drug discriminative stimulus effects has the potential to influence drug intake.

\subsection{Caffeine}

\subsubsection{Evidence from humans}

In an early retrospective study, Haertzen et al. (1983) queried opiate abusers about their initial responses to caffeine. Although these participants claimed that their initial responses to heroin and cocaine predicted subsequent use of these drugs, they reported that their initial responses to caffeine were unpleasant and not related to future use. To our knowledge, no longitudinal studies have examined the initial responses to caffeine in relation to future use. One 
challenge to conducting longitudinal studies on early responses to caffeine is that caffeine use begins early (Frary et al., 2005), usually in the form of caffeinated sodas. Because of the widespread use of these drinks and the relatively subtle acute effects of low doses of caffeine, it is difficult to assess early responses under noncontrolled conditions.

Several laboratory-based studies have examined acute subjective responses to caffeine in adults as predictors of choice or consumption of the drug in the laboratory (Griffiths and Woodson, 1988; Stern et al., 1989). These studies support the idea that pleasant caffeine-induced effects such as mental arousal and decreased fatigue predict drug choice, whereas unpleasant effects such as jitteriness or anxiety predict non-choice of caffeine. There is also indirect evidence that negative subjective responses predict low caffeine use. Patients with panic disorder experience anxiety from caffeine, and consume less of it than healthy controls (Boulenger et al., 1984; Charney et al., 1985; Lee et al., 1988; Uhde et al., 1984). Moreover, in both panic disorder patients and healthy controls, individuals with a certain polymorphism of the adenosine receptor gene are more likely to experience anxiety from an acute dose of the drug (Alsene et al., 2003; Charney et al., 1985; Childs et al., 2008; Lee et al., 1988; Uhde et al., 1984). Yang et al. (2010) recently reviewed evidence for the contribution of genetic factors in responses to caffeine in humans and found evidence for genetic contributions to the positive vs. negative subjective or physiological effects of caffeine (e.g., feelings of arousal, anxiety or insomnia), level of habitual caffeine consumption and caffeine metabolism. Indeed, recent genome-wide association analyses involving thousands of people have identified significant associations with caffeine intake for single nucleotide polymorphisms that suggest a role for genes involved in the metabolism of caffeine or the constituents of coffee (Amin et al., 2011; Cornelis et al., 2011; Sulem et al., 2001). Whether there is a role for these genes in caffeine sensitivity has not been explored.

\subsubsection{Evidence from nonhumans}

Relatively few studies have examined initial acute responses to caffeine in relation to self-administration in nonhumans. However, mechanistic studies point to a role for the $A_{2 A}$ receptor subtype in both caffeine consumption and locomotor activation (El Yacoubi et al., 2000, 2005; Yang et al., 2009), using $A_{2 A}$ knockout mice. In another study using $A_{1}$ knockout mice, no evidence for a role of the $A_{1}$ receptor subtype in caffeine consumption was found (Rieg et al., 2007) and a lesser role than that of the $A_{2 A}$ receptor was found for caffeine-induced locomotor stimulation (Yang et al., 2009). Though these are interesting results that suggest some common mechanisms underlying sensitivity and intake, they do not directly address the question of whether initial sensitivity to caffeine predicts future intake.

\subsection{Opiates}

\subsubsection{Evidence from humans}

In an early retrospective study, Haertzen et al. (1983) reported that opiate abusers liked their first experiences with heroin and other opiates more than they liked 11 other types of drugs that they had used, and that opiates were their preferred and primary drug of choice from the beginning. Conducting a retrospective study that included non-drug-abusing volunteers, Bieber et al. (2008) recruited 20 opioid abusers in a treatment center and 20 controls, all of whom had first received opiates for pain control. Participants completed a retrospective questionnaire reporting the feelings of euphoria and well-being they experienced upon their first use of an opiate drug. The drug-abusing participants reported having experienced greater euphoria upon their first use than the control group. There are no longitudinal studies on initial responses to opiates in relation to subsequent abuse, although such information would be valuable because of the widespread medical use of opiates as well as the recently increasing prevalence of abuse (Manubay et al., 2011; Maxwell, 2011). Fortunately, only a very small proportion of patients who receive opiates for pain control progress to develop problems with abuse (Hojsted and Sjogren, 2007).

Controlled studies with healthy volunteers do indicate that acute responses to opiates vary markedly across individuals (Comer et al., 2010; Lasagna et al., 1955; McAuliffe, 1975; Zacny and Gutierrez, 2003; Zacny et al., 1994, 1992), from pleasant to unpleasant. Whether these initial subjective effects of opiates predict repeated use or choice over a placebo has not yet been studied.

\subsubsection{Evidence from nonhumans}

The question of the relationship between initial sensitivity and self-administration of opiates has received relatively little attention in nonhuman studies. C57BL/6J inbred strain mice exhibit a larger initial stimulant response to morphine than do DBA/2J mice (Belknap et al., 1989), and DBA/2J mice exhibit a locomotor depressant response to morphine early after administration (Phillips et al., 1994). Consistent with the idea that stimulation is related to reward, morphine supports intravenous self-administration in C57BL/6J, but not DBA/2J mice (Elmer et al., 2010). These data are in agreement with two-bottle choice drinking studies showing greater morphine consumption in the C57BL/6J than DBA/2J strain (Belknap et al., 1993; Horowitz et al., 1977). Thus, for these two strains, the data suggest that greater initial sensitivity to stimulant effects of an opioid is associated with greater reinforcement, and greater sensitivity to depressant effects reduces consumption. However, in another set of 4 strains, oral self-administration of the opioid, etonitazene, was not associated with sensitivity to etonitazene-induced locomotor stimulation or other effects (Elmer et al., 1995). A few studies in single gene mutant mice are also relevant. Not surprisingly, mu-opioid receptor knockout mice do not self-administer morphine and show reduced sensitivity to morphine-induced locomotor stimulation (Sora et al., 2001). In mice lacking protein kinase $C$ epsilon, increased susceptibility to morphine self-administration was associated with enhanced sensitivity to morphine's analgesic effects, compared to their non-mutant counterparts (Newton et al., 2007). Mice lacking the NK1 receptor, the preferred receptor for substance $P$, exhibited heightened sensitivity to locomotor depressant effects of morphine, as well as reduced self-administration of morphine (Ripley et al., 2002). These results mirror those for DBA/2J, compared to C57BL/6J, mice. Overall, the data support a positive relationship between sensitivity to stimulant effects of opioids and opioid selfadministration and a negative relationship between sensitivity to depressant effects of opioids and opioid self-administration.

\section{Conclusions}

So, do initial responses to drugs predict future use or abuse? We have reviewed the limited evidence that early responses to drugs predict use or abuse in humans and nonhumans. First, we confirm that there are marked individual differences in initial acute responses to drugs, and some of these differences are genetic. Second, we confirm that certain direct effects of drugs appear to be protective against future use, such as, in humans, the flushing response to alcohol and perhaps the anxiety response to caffeine. Third, we find some evidence that euphoria and stimulation facilitate repeated use across several classes of drugs, including opiates and stimulants in humans, although the evidence for stimulants in animals is more mixed. From this review, we conclude that initial positive or negative effects of drugs probably influence the likelihood of continuing use in the short term, but their relationship with 
full dependence is less clear. By definition, early use must precede escalation of use, which precedes dependence. Therefore, there is likely to be some relation between initial responses and dependence. However, the contribution of the initial acute effect of the drug is probably minor, compared to the multitude of other variables that contribute to excessive drug use. These include cognitive factors related to decision-making, physiological factors related to stress, as well as processes of neural adaptation, learning, tolerance, sensitization, and physical dependence that only develop with continued ingestion of the drugs.

We have identified gaps in the literature, methodological challenges and directions for future research. Longitudinal research documenting initial drug effects, and following probands across their drug-taking trajectories, is the gold standard. Longitudinal studies would be of particular interest with opiates, for example, and with cigarette smokers. Animal models also offer a valuable tool for studying this relationship, and for particular studying genetic factors. Initial drug responses can easily be obtained in naïve animals, genetic characteristics and context can be controlled and drug dose and purity are not an issue. Relatively few nonhuman studies have followed the complete time progression of the dependence process, beyond the initial self-administration period. To coordinate the human and nonhuman studies, there is a need to develop and refine drug-abuse related measures that are directly comparable in humans and animals (Crabbe et al., 2010; O’Dell and Khroyan, 2009; Stephens et al., 2011). Although the relationship between initial drug sensitivity and risk for abuse or dependence is not likely to be simple, further exploration is likely to solidify which traits are of greatest relevance and thus, of greatest predictive value.

\section{Acknowledgments}

The authors were supported by DA02812 (HdW), DA032015 (HdW), AA010760 (TP), AA016655 (TP), DA018165 (TP), and the Department of Veterans Affairs (TP). John Crabbe, Chris-Ellyn Johanson, Matthew Kirkpatrick, James Zacny and Emma Childs provided valuable comments on the manuscript.

\section{References}

Agabio, R., et al., 2001. Alcohol stimulates motor activity in selectively bred Sardinian alcohol-preferring (sP), but not in Sardinian alcohol-nonpreferring (sNP), rats. Alcohol 23, 123-126.

Alsene, K., et al., 2003. Association between $\mathrm{A}_{2 \mathrm{a}}$ receptor gene polymorphisms and caffeine-induced anxiety. Neuropsychopharmacology 28, 1694-1702.

Amin, N., et al., 2011. Genome-wide association analysis of coffee drinking suggests association with CYP1A1/CYP1A2 and NRCAM. Molecular Psychiatry, http://dx.doi.org/10.1038/mp.2011.101

Amit, Z., et al., 1977. Possible involvement of acetaldehyde, norepinephrine and their tetrahydroisoquinoline derivatives in the regulation of ethanol selfadministration. Drug and Alcohol Dependence 2, 495-500.

APA, 1994. Diagnostic and Statistical Manual of Mental Disorders: DSM-IV. American Psychiatric Association, Washington, DC.

Audrain-McGovern, J., et al., 2007. The role of CYP2A6 in the emergence of nicotine dependence in adolescents. Pediatrics 119, e264-e274.

Balster, R.L., Bigelow, G.E., 2003. Guidelines and methodological reviews concerning drug abuse liability assessment. Drug and Alcohol Dependence 70, S13-S40.

Bass, C.E., et al., 2002. SR-141716A-induced stimulation of locomotor activity. A structure-activity relationship study. Pharmacology Biochemistry and Behavior $74,31-40$.

Belknap, J.K., et al., 1989. Genetic dissociation of multiple morphine effects among C57BL/6J, DBA/2J and C3H/HeJ inbred mouse strains. Physiology and Behavior $46,69-74$.

Belknap, J.K., et al., 1993. Voluntary consumption of morphine in 15 inbred mouse strains. Psychopharmacology 112, 352-358.

Benowitz, N.L., Jacob 3rd, P., 1994. Metabolism of nicotine to cotinine studied by a dual stable isotope method. Clinical Pharmacology and Therapeutics 56, 483-493.

Bergstrom, H.C., et al., 2003. Reverse selection for differential response to the locomotor stimulant effects of ethanol provides evidence for pleiotropic genetic influence on locomotor response to other drugs of abuse. Alcoholism, Clinical and Experimental Research 27, 1535-1547.

Besheer, J., et al., 2012. The effects of repeated corticosterone exposure on the interoceptive effects of alcohol in rats. Psychopharmacology 220, 809-822.
Bevins, R.A., et al., 1997. Individual differences in response to novelty, amphetamineinduced activity and drug discrimination in rats. Behavioural Pharmacology 8 , 113-123.

Bieber, C.M., et al., 2008. Retrospective accounts of initial subjective effects of opioids in patients treated for pain who do or do not develop opioid addiction: a pilot case-control study. Experimental and Clinical Psychopharmacology 16 429-434.

Boehm 2nd, S.L., et al., 2000. Sensitivity to ethanol-induced motor incoordination in FAST and SLOW selectively bred mice. Pharmacology Biochemistry and Behavior $66,241-247$.

Boulenger, J.P., et al., 1984. Increased sensitivity to caffeine in patients with panic disorders. Preliminary evidence. Archives of General Psychiatry 41, 1067-1071.

Boyle, A.E., Gill, K.J., 2009. Genetic analysis of the psychostimulant effects of nicotine in chromosome substitution strains and $\mathrm{F} 2$ crosses derived from $\mathrm{A} / \mathrm{J}$ and C57BL/6J progenitors. Mammalian Genome 20, 34-42.

Broadbent, J., et al., 2002. Ethanol-induced conditioned taste aversion in 15 inbred mouse strains. Behavioral Neuroscience 116, 138-148.

Brower, V.G., et al., 2002. Rat strain differences in nicotine self-administration using an unlimited access paradigm. Brain Research 930, 12-20.

Buchmann, A.F., et al., 2011. Early smoking onset may promise initial pleasurable sensations and later addiction. Addiction Biology, http://dx.doi.org/10.1111/j.1369-1600.2011.00377.x.

Caggiula, A.R., et al., 2009. The role of nicotine in smoking: a dual-reinforcement model. Nebraska Symposium on Motivation 55, 91-109.

Cailhol, S., Mormede, P., 2002. Conditioned taste aversion and alcohol drinking: strain and gender differences. Journal of Studies on Alcohol 63, 91-99.

Carter, B., et al., 2004. A meta-analytic review of the CYP2A6 genotype and smoking behavior. Nicotine and Tobacco Research 6, 221-227.

Carter, L.P., Griffiths, R.R., 2009. Principles of laboratory assessment of drug abuse liability and implications for clinical development. Drug and Alcohol Dependence 105 (Suppl. 1), S14-S25.

Chait, L.D., Perry, J.L., 1992. Factors influencing self-administration of, and subjective response to, placebo marijuana. Behavioural Pharmacology 3, 545-552.

Chait, L.D., 1993. Factors influencing the reinforcing and subjective effects of Damphetamine in humans. Behavioural Pharmacology 4, 191-199.

Changeux, J.P., 2010. Nicotine addiction and nicotinic receptors: lessons from genetically modified mice. Nature Reviews Neuroscience 11, 389-401.

Charney, D.S., et al., 1985. Increased anxiogenic effects of caffeine in panic disorders. Archives of General Psychiatry 42, 233-243.

Chaudhri, N., et al., 2006. Complex interactions between nicotine and nonpharmacological stimuli reveal multiple roles for nicotine in reinforcement. Psychopharmacology 184, 353-366.

Chen, X., et al., 2003. Sensations from initial exposure to nicotine predicting adolescent smoking in China: a potential measure of vulnerability to nicotine. Nicotine and Tobacco Research 5, 455-463.

Chester, J.A., et al., 2003. High- and low-alcohol-preferring mice show differences in conditioned taste aversion to alcohol. Alcoholism, Clinical and Experimental Research 27, 12-18.

Childs, E., et al., 2008. Association between ADORA2A and DRD2 polymorphisms and caffeine-induced anxiety. Neuropsychopharmacology 33, 2791-2800.

Chutuape, M.A., de Wit, H., 1994. Relationship between subjective effects and drug preferences: ethanol and diazepam. Drug and Alcohol Dependence 34, 243-251.

Cloninger, C.R., et al., 1981. Inheritance of alcohol abuse. Cross-fostering analysis of adopted men. Archives of General Psychiatry 38, 861-868.

Colombo, G., et al., 2000. Different sensitivity to ethanol in alcohol-preferring sP and -nonpreferring sNP rats. Alcoholism, Clinical and Experimental Research $24,1603-1608$.

Comer, S.D., et al., 2010. Evaluation of potential sex differences in the subjective and analgesic effects of morphine in normal, healthy volunteers. Psychopharmacology $208,45-55$.

Conrod, P.J., et al., 2001. Reliability and validity of alcohol-induced heart rate increase as a measure of sensitivity to the stimulant properties of alcohol. Psychopharmacology 157, 20-30.

Cornelis, M.C., et al., 2011. Genome-wide meta-analysis identifies regions on 7p21 (AHR) and 15q24 (CYP1A2) as determinants of habitual caffeine consumption. PLoS Genetics 7, e1002033.

Corrigall, W.A., Coen, K.M., 1989. Nicotine maintains robust self-administration in rats on a limited-access schedule. Psychopharmacology 99, 473-478.

Crabbe, J.C., et al., 1987. Mice genetically selected for differences in open-field activity after ethanol. Pharmacology Biochemistry and Behavior 27, 577-581.

Crabbe, J.C., et al., 2006. Alcohol-related genes: contributions from studies with genetically engineered mice. Addiction Biology 11, 195-269.

Crabbe, J.C., et al., 2010. The complexity of alcohol drinking: studies in rodent genetic models. Behavior Genetics 40, 737-750.

Cummings, J.A., et al., 2011. Effects of a selectively bred novelty-seeking phenotype on the motivation to take cocaine in male and female rats. Biology of Sex Differences 2, 3 .

Darmani, N.A., 2001. The cannabinoid CB1 receptor antagonist SR 141716A reverses the antiemetic and motor depressant actions of WIN 55,212-2. European Journal of Pharmacology 430, 49-58.

Davidson, E.S., et al., 1993. Variability in subjective responses to cocaine: initial experiences of college students. Addictive Behaviors 18, 445-453.

Davidson, E.S., Schenk, S., 1994. Variability in subjective responses to marijuana: initial experiences of college students. Addictive Behaviors 19, 531-538.

Davis, B.A., et al., 2008. The effects of novelty-seeking phenotypes and sex differences on acquisition of cocaine self-administration in selectively bred high-responder 
and low-responder rats. Pharmacology Biochemistry and Behavior 90, 331-338.

de Wit, H., et al., 1986. Individual differences in the reinforcing and subjective effects of amphetamine and diazepam. Drug and Alcohol Dependence 16, 341-360.

de Wit, H., et al., 1987. The reinforcing properties of amphetamine in overweight subjects and subjects with depression. Clinical Pharmacology and Therapeutics 42, 127-136.

de Wit, H., Griffiths, R.R., 1991. Testing the abuse liability of anxiolytic and hypnotic drugs in humans. Drug and Alcohol Dependence 28, 83-111.

de Wit, H., Bodker, B., 1994. Personality and drug preferences in normal volunteers. International Journal of the Addictions 29, 1617-1630.

de Wit, H., 1998. Individual differences in acute effects of drugs in humans: their relevance to risk for abuse. NIDA Research Monograph 169, 176-187.

Deminiere, J.M., et al., 1989. Experimental approach to individual vulnerability to psychostimulant addiction. Neuroscience and Biobehavioral Reviews 13 141-147.

DiFranza, J.R., et al., 2004. Recollections and repercussions of the first inhaled cigarette. Addictive Behaviors 29, 261-272.

DiFranza, J.R., et al., 2007. Susceptibility to nicotine dependence: the development and assessment of nicotine dependence in youth 2 study. Pediatrics 120 , e974-e983.

Dubreucq, S., et al., 2012. Cannabinoid type 1 receptors located on single-minded 1-expressing neurons control emotional behaviors. Neuroscience 204, 230-244. Edenberg, H.J., 2007. The genetics of alcohol metabolism: role of alcohol dehydrogenase and aldehyde dehydrogenase variants. Alcohol Research and Health 30, 5-13.

Ehlers, C.L., Schuckit, M.A., 1990. EEG fast frequency activity in the sons of alcoholics. Biological Psychiatry 27, 631-641.

Eissenberg, T., Balster, R.L., 2000. Initial tobacco use episodes in children and adolescents: current knowledge, future directions. Drug and Alcohol Dependence 59 (Suppl. 1), S41-S60.

El Yacoubi, M., et al., 2000. The stimulant effects of caffeine on locomotor behaviour in mice are mediated through its blockade of adenosine $\mathrm{A}(2 \mathrm{~A})$ receptors. British Journal of Pharmacology 129, 1465-1473.

El Yacoubi, M., et al., 2005. Reduced appetite for caffeine in adenosine $\mathrm{A}(2 \mathrm{~A})$ receptor knockout mice. European Journal of Pharmacology 519, 290-291.

Elmer, G.I., et al., 1995. Opioid operant self-administration, analgesia, stimulation and respiratory depression in mu-deficient mice. Psychopharmacology 117, 23-31.

Elmer, G.I., et al., 2010. Qualitative differences between C57BL/6J and DBA/2J mice in morphine potentiation of brain stimulation reward and intravenous selfadministration. Psychopharmacology 208, 309-321.

Eng, M.Y., et al., 2005. The level of response to alcohol in daughters of alcoholics and controls. Drug and Alcohol Dependence 79, 83-93.

Everitt, B.J., et al., 2008. Review. Neural mechanisms underlying the vulnerability to develop compulsive drug-seeking habits and addiction. Philosophical Transactions of the Royal Society of London, Series B: Biological Sciences 363, 3125-3135.

Fattore, L., et al., 2001. Intravenous self-administration of the cannabinoid CB1 receptor agonist WIN 55,212-2 in rats. Psychopharmacology 156, 410-416.

Fergusson, D.M., et al., 2003. Early reactions to cannabis predict later dependence. Archives of General Psychiatry 60, 1033-1039.

Files, F.J., et al., 1996. Initiation of ethanol self-administration by the sucrosesubstitution method with HAS and LAS rats. Alcoholism, Clinical and Experimental Research 20,677-681.

Fischman, M.W., Foltin, R.W., 1991. Utility of subjective-effects measurements in assessing abuse liability of drugs in humans. British Journal of Addiction 86, 1563-1570.

Flagel, S.B., et al., 2010. An animal model of genetic vulnerability to behavioral disinhibition and responsiveness to reward-related cues: implications for addiction. Neuropsychopharmacology 35, 388-400.

Frary, C.D., et al., 2005. Food sources and intakes of caffeine in the diets of persons in the United States. Journal of the American Dietetic Association 105, 110-113.

Froehlich, J.C., et al., 1988. Differences in response to the aversive properties of ethanol in rats selectively bred for oral ethanol preference. Pharmacology Biochemistry and Behavior 31, 215-222.

Garcia-Fuster, M.J., et al., 2010. Impact of cocaine on adult hippocampal neurogenesis in an animal model of differential propensity to drug abuse. European Journal of Neuroscience 31, 79-89.

Gill, K.J., Boyle, A.E., 2005. Genetic basis for the psychostimulant effects of nicotine: a quantitative trait locus analysis in $\mathrm{AcB} / \mathrm{BcA}$ recombinant congenic mice. Genes, Brain and Behavior 4, 401-411.

Gordh, A.H., et al., 2011. Stress and consumption of alcohol in humans with a type 1 family history of alcoholism in an experimental laboratory setting. Pharmacology Biochemistry and Behavior 99, 696-703.

Gordon, T.L., et al., 1993. P and NP rats respond differently to the discriminative stimulus effects of nicotine. Pharmacology Biochemistry and Behavior 45, 305-308.

Grahame, N.J., et al., 2000. Ethanol locomotor sensitization, but not tolerance correlates with selection for alcohol preference in high- and low-alcohol preferring mice. Psychopharmacology 151, 252-260.

Grant, B.F., 1998. The impact of a family history of alcoholism on the relationship between age at onset of alcohol use and DSM-IV alcohol dependence: results from the National Longitudinal Alcohol Epidemiologic Survey. Alcohol Health and Research World 22, 144-147.

Griffiths, R.R., Woodson, P.P., 1988. Reinforcing effects of caffeine in humans. Journal of Pharmacology and Experimental Therapeutics 246, 21-29.
Haberstick, B.C., et al., 2011. Common and drug-specific genetic influences on subjective effects to alcohol, tobacco and marijuana use. Addiction 106, 215-224.

Haertzen, C.A., et al., 1983. Reinforcements from the first drug experience can predict later drug habits and/or addiction: results with coffee, cigarettes, alcohol, barbiturates, minor and major tranquilizers, stimulants, marijuana, hallucinogens, heroin, opiates and cocaine. Drug and Alcohol Dependence 11 147-165.

Hart, A.B., de Wit, H., Palmer, A.A., 2012. Genetic factors modulating the response to stimulant drugs in humans. Current Topics in Behavioral Neurosciences [Epub ahead of print] PMID: 22261702 [PubMed-as supplied by publisher].

Hendler, R.A., et al., 2011. Stimulant and sedative effects of alcohol. Current Topics in Behavioral Neurosciences, http://dx.doi.org/10.1007/7854_2011_135.

Ho, M.K., Tyndale, R.F., 2007. Overview of the pharmacogenomics of cigarette smoking. Pharmacogenomics Journal 7, 81-98.

Hodge, C.W., et al., 1999. Supersensitivity to allosteric GABA(A) receptor modulators and alcohol in mice lacking PKCepsilon. Nature Neuroscience 2, 997-1002.

Hojsted, J., Sjogren, P., 2007. Addiction to opioids in chronic pain patients: a literature review. European Journal of Pain 11, 490-518.

Holdstock, L., de Wit, H., 2001. Individual differences in responses to ethanol and D-amphetamine: a within-subject study. Alcoholism, Clinical and Experimenta Research 25, 540-548.

Horowitz, G.P., Whitney, G., 1975. Alcohol-induced conditioned aversion: genotypie specificity in mice (Mus musculus). Journal of Comparative and Physiological Psychology 89, 340-346.

Horowitz, G.P., et al., 1977. Morphine ingestion: genetic control in mice. Psychopharmacology 52, 119-122.

Hu, M.C., et al., 2006. Epidemiology and correlates of daily smoking and nicotine dependence among young adults in the United States. American Journal of Public Health 96, 299-308.

Isse, T., et al., 2002. Diminished alcohol preference in transgenic mice lacking aldehyde dehydrogenase activity. Pharmacogenetics 12, 621-626.

Isse, T., et al., 2005. Aldehyde dehydrogenase 2 gene targeting mouse lacking enzyme activity shows high acetaldehyde level in blood, brain, and liver after ethano gavages. Alcoholism, Clinical and Experimental Research 29, 1959-1964.

Jasinski, D.R., 1991. History of abuse liability testing in humans. British Journal of Addiction 86, 1559-1562.

Johanson, C.E., Uhlenhuth, E.H., 1980. Drug preference and mood in humans: Damphetamine. Psychopharmacology 71, 275-279.

Justinova, Z., et al., 2008. Blockade of THC-seeking behavior and relapse in monkeys by the cannabinoid $\mathrm{CB}_{1}$-receptor antagonist rimonabant. Neuropsychopharmacology 33, 2870-2877.

Kamens, H.M., et al., 2005. Sensitivity to psychostimulants in mice bred for high and low stimulation to methamphetamine. Genes, Brain and Behavior 4, 110-125.

Kandel, D.B., et al., 2007. On the development of nicotine dependence in adolescence. Drug and Alcohol Dependence 91, 26-39.

Karahanian, E., et al., 2011. Ethanol as a prodrug: brain metabolism of ethanol mediates its reinforcing effects. Alcoholism, Clinical and Experimental Research 35 606-612.

Kim, K.S., et al., 2011. Mice lacking adenylyl cyclase type 5 (AC5) show increased ethanol consumption and reduced ethanol sensitivity. Psychopharmacology 215, 391-398.

Kirk, J.M., et al., 1998. Effects of expectancies on subjective responses to oral delta9tetrahydrocannabinol. Pharmacology Biochemistry and Behavior 59, 287-293.

Kollins, S.H., et al., 2001. Assessing the abuse potential of methylphenidate in nonhuman and human subjects: a review. Pharmacology Biochemistry and Behavior 68, 611-627.

Krimmer, E.C., 1992. Biphasic effects of ethanol tested with drug discrimination in HAD and LAD rats. Pharmacology Biochemistry and Behavior 43, 1233-1240.

Krimmer, E.C., Schechter, M.D., 1992. HAD and LAD rats respond differently to stimulating effect but not discriminative effects of ethanol. Alcohol 9, 71-74.

Kurtz, D.L., et al., 1996. Genetic differences in tolerance and sensitization to the sedative/hypnotic effects of alcohol. Pharmacology Biochemistry and Behavior 53, 585-591.

Lambert, N.M., et al., 2006. Subjective responses to initial experience with cocaine: an exploration of the incentive-sensitization theory of drug abuse. Addiction $101,713-725$.

Lasagna, L., et al., 1955. Drug-induced mood changes in man. I. Observations on healthy subjects, chronically ill patients, and postaddicts. The Journal of the American Medical Association 157, 1006-1020.

Le Strat, Y., et al., 2009. First positive reactions to cannabis constitute a priority risk factor for cannabis dependence. Addiction 104, 1710-1717.

Lecca, D., et al., 2006. Monitoring extracellular dopamine in the rat nucleus accumbens shell and core during acquisition and maintenance of intravenous WIN 55,212-2 self-administration. Psychopharmacology 188, 63-74.

Lee, M.A., et al., 1988. Anxiogenic effects of caffeine on panic and depressed patients. American Journal of Psychiatry 145, 632-635.

Lott, D.C., et al., 2005. Dopamine transporter gene associated with diminished subjective response to amphetamine. Neuropsychopharmacology 30, 602-609.

Lumeng, L., et al., 1982. Different sensitivities to ethanol in alcohol-preferring and -nonpreferring rats. Pharmacology Biochemistry and Behavior 16, 125-130.

Malaiyandi, V., et al., 2006. Impact of CYP2A6 genotype on pretreatment smoking behaviour and nicotine levels from and usage of nicotine replacement therapy. Molecular Psychiatry 11, 400-409.

Mandt, B.H., et al., 2008. Individual differences in cocaine-induced locomotor activity in male Sprague-Dawley rats and their acquisition of and motivation to selfadminister cocaine. Psychopharmacology 201, 195-202. 
Mandt, B.H., et al., 2012. Acquisition of cocaine self-administration in male SpragueDawley rats: effects of cocaine dose but not initial locomotor response to cocaine. Psychopharmacology 219, 1089-1097.

Mantsch, J.R. et al., 2001. Predictable individual differences in the initiation of cocaine self-administration by rats under extended-access conditions are dosedependent. Psychopharmacology 157, 31-39.

Manubay, J.M., et al., 2011. Prescription drug abuse: epidemiology, regulatory issues, chronic pain management with narcotic analgesics. Primary Care; Clinics in Office Practice 38, 71-90, vi.

Marks, M.J., et al., 1989. Genetic influences on nicotine responses. Pharmacology Biochemistry and Behavior 33, 667-678.

Martelle, J.L., Nader, M.A., 2009. A within-subject assessment of the discriminative stimulus and reinforcing effects of self-administered cocaine in rhesus monkeys. Psychopharmacology 203, 343-353.

Maxwell, C.R., et al., 2010. Acetate causes alcohol hangover headache in rats. PLoS One 5 , e15963.

Maxwell, J.C., 2011. The prescription drug epidemic in the United States: a perfect storm. Drug and Alcohol Review 30, 264-270.

McAuliffe, W.E., 1975. A second look at first effects: the subjective effects of opiates on nonaddicts. Journal of Drug Issues 5, 369-399.

McGregor, I.S., et al., 1996. Aversive effects of the synthetic cannabinoid CP 55,940 in rats. Pharmacology Biochemistry and Behavior 53, 657-664.

McMillan, D.E., Li, M., 1999. Lack of difference between HAD and LAD rats in the stimulus generalization of ethanol to nicotine. Behavioural Pharmacology 10, 809-812.

McMillan, D.E., et al., 1999. Differences between alcohol-preferring and alcoholnonpreferring rats in ethanol generalization. Pharmacology Biochemistry and Behavior 64, 415-419.

McMillan, D.E., Li, M., 2001. LAD rats learn a three-key drug discrimination more rapidly and achieve a higher level of performance than HAD rats. Behavioural Pharmacology 12, 545-548.

Mendizabal, V., et al., 2006. Involvement of kappa/dynorphin system in WIN 55,2122 self-administration in mice. Neuropsychopharmacology 31, 1957-1966.

Meschler, J.P., et al., 2000. $\mathrm{D}_{2}$, but not $\mathrm{D}_{1}$ dopamine receptor agonists potentiate cannabinoid-induced sedation in nonhuman primates. Journal of Pharmacology and Experimental Therapeutics 292, 952-959.

Mitchell, S.H., et al., 1996. Interaction of expectancy and the pharmacological effects of D-amphetamine: subjective effects and self-administration. Psychopharmacology $125,371-378$

Moss, H.B., et al., 2007. Subtypes of alcohol dependence in a nationally representative sample. Drug and Alcohol Dependence 91, 149-158.

Murray, J.E., Bevins, R.A., 2010. Cannabinoid conditioned reward and aversion: behavioral and neural processes. ACS Chemical Neuroscience 1, 265-278.

Naassila, M., et al., 2002. Low ethanol sensitivity and increased ethanol consumption in mice lacking adenosine $\mathrm{A}(2 \mathrm{~A})$ receptors. Journal of Neuroscience 22, 10487-10493.

Newlin, D.B., Thomson, J.B., 1990. Alcohol challenge with sons of alcoholics: a critical review and analysis. Psychological Bulletin 108, 383-402.

Newlin, D.B., Renton, R.M., 2010. High risk groups often have higher levels of alcohol response than low risk: the other side of the coin. Alcoholism, Clinical and Experimental Research 34, 199-202 (Author reply 203-195).

Newton, P.M., et al., 2007. Increased response to morphine in mice lacking protein kinase C epsilon. Genes, Brain and Behavior 6, 329-338.

O’Dell, L.E., Khroyan, T.V., 2009. Rodent models of nicotine reward: what do they tell us about tobacco abuse in humans? Pharmacology Biochemistry and Behavior 91, 481-488.

Overstreet, D.H., 1995. Differential effects of nicotine in inbred and selectively bred rodents. Behavior Genetics 25, 179-185.

Ozburn, A.R., et al., 2010. Behavioral differences between C57BL/6J $\times$ FVB/NJ and C57BL/6J $\times$ NZB/B1NJ F1 hybrid mice: relation to control of ethanol intake. Behavior Genetics 40, 551-563.

Paivarinta, P., Korpi, E.R., 1993. Voluntary ethanol drinking increases locomotor activity in alcohol-preferring AA rats. Pharmacology Biochemistry and Behavior 44, 127-132.

Panagis, G., et al., 2008. Behavioral pharmacology of cannabinoids with a focus on preclinical models for studying reinforcing and dependence-producing properties. Current Drug Abuse Reviews 1, 350-374.

Panlilio, L.V., et al., 1996. Cocaine self-administration increased by compounding discriminative stimuli. Psychopharmacology 125, 202-208.

Perkins, K.A., et al., 2000. Greater sensitivity to subjective effects of nicotine in nonsmokers high in sensation seeking. Experimental and Clinical Psychopharmacology 8, 462-471.

Perkins, K.A., et al., 2001. Reinforcing effects of nicotine as a function of smoking status. Experimental and Clinical Psychopharmacology 9, 243-250.

Perkins, K.A., et al., 2008. Association of retrospective early smoking experiences with prospective sensitivity to nicotine via nasal spray in nonsmokers. Nicotine and Tobacco Research 10, 1335-1345.

Phillips, T.J., Crabbe, J.C., 1991. Behavioral studies of genetic differences in alcohol action. In: Crabbe, J.C., Harris, R.A. (Eds.), The Genetic Basis of Alcohol and Drug Actions. Plenum Press, New York, pp. 25-104.

Phillips, T.J., et al., 1994. Behavioral sensitization to drug stimulant effects in C57BL/6J and DBA/2J inbred mice. Behavioral Neuroscience 108, 789-803.

Phillips, T.J., et al., 1995. Effects of acute and repeated ethanol exposures on the locomotor activity of BXD recombinant inbred mice. Alcoholism, Clinical and Experimental Research 19, 269-278.
Phillips, T.J., et al., 2002. Forward, relaxed, and reverse selection for reduced and enhanced sensitivity to ethanol's locomotor stimulant effects in mice. Alcoholism, Clinical and Experimental Research 26, 593-602.

Phillips, T.J., et al., 2005. Genetic correlational analyses of ethanol reward and aversion phenotypes in short-term selected mouse lines bred for ethanol drinking or ethanol-induced conditioned taste aversion. Behavioral Neuroscience 119, 892-910.

Piazza, P.V., et al., 1989. Factors that predict individual vulnerability to amphetamine self-administration. Science 245, 1511-1513.

Pierre, P.J., Vezina, P., 1997. Predisposition to self-administer amphetamine: the contribution of response to novelty and prior exposure to the drug. Psychopharmacology 129, 277-284.

Quintanilla, M.E., 1999. Effect of low doses of ethanol on spontaneous locomotor activity in UChB and UChA rats. Addiction Biology 4, 443-448.

Quintanilla, M.E., et al., 2001. Differences in sensitivity to the aversive effects of ethanol in low-alcohol drinking (UChA) and high-alcohol drinking (UChB) rats. Alcohol 23, 177-182.

Riebe, C.J., Wotjak, C.T., 2011. Endocannabinoids and stress. Stress 14 384-397.

Rieg, T., et al., 2007. Adenosine $A_{1}$ receptors determine effects of caffeine on total fluid intake but not caffeine appetite. European Journal of Pharmacology 555, 174-177.

Ripley, T.L., et al., 2002. Lack of self-administration and behavioural sensitisation to morphine, but not cocaine, in mice lacking NK1 receptors. Neuropharmacology $43,1258-1268$.

Risinger, F.O., Cunningham, C.L., 1992. Genetic differences in ethanol-induced hyperglycemia and conditioned taste aversion. Life Sciences 50, PL113-PL118.

Risinger, F.O., et al., 1994. Motivational properties of ethanol in mice selectively bred for ethanol-induced locomotor differences. Psychopharmacology 116 207-216.

Risinger, F.O., Cunningham, C.L., 1998. Ethanol-induced conditioned taste aversion in BXD recombinant inbred mice. Alcoholism, Clinical and Experimental Research $22,1234-1244$

Risner, M.E., Goldberg, S.R., 1983. A comparison of nicotine and cocaine selfadministration in the dog: fixed-ratio and progressive-ratio schedules of intravenous drug infusion. Journal of Pharmacology and Experimental Therapeutics 224, 319-326.

Robinson, S.F., et al., 1996. Inbred mouse strains vary in oral self-selection of nicotine. Psychopharmacology 124, 332-339.

Rodd, Z.A., et al., 2004. Low-dose stimulatory effects of ethanol during adolescence in rat lines selectively bred for high alcohol intake. Alcoholism, Clinical and Experimental Research 28, 535-543.

Rush, C.R., et al., 2001. Reinforcing and subject-rated effects of methylphenidate and D-amphetamine in non-drug-abusing humans. Journal of Clinical Psychopharmacology 21, 273-286.

Sannerud, C.A., et al., 1994. The effects of sertraline on nicotine self-administration and food-maintained responding in squirrel monkeys. European Journal of Pharmacology 271, 461-469.

Schechter, M.D., 1992. Locomotor activity but not conditioned place preference is differentially affected by a moderate dose of ethanol administered to P and NP rats. Alcohol 9, 185-188.

Schuckit, M.A., 1984a. Relationship between the course of primary alcoholism in men and family history. Journal of Studies on Alcohol 45, 334-338.

Schuckit, M.A., 1984b. Subjective responses to alcohol in sons of alcoholics and control subjects. Archives of General Psychiatry 41, 879-884.

Schuckit, M.A., 1985a. Genetics and the risk for alcoholism. The Journal of the American Medical Association 254, 2614-2617.

Schuckit, M.A., 1985b. Ethanol-induced changes in body sway in men at high alcoholism risk. Archives of General Psychiatry 42, 375-379.

Schuckit, M.A., 1987. Biological vulnerability to alcoholism. Journal of Consulting and Clinical Psychology 55, 301-309.

Schuckit, M.A., et al., 1987a. Plasma cortisol levels following ethanol in sons of alcoholics and controls. Archives of General Psychiatry 44, 942-945.

Schuckit, M.A., et al., 1987b. Serum prolactin levels in sons of alcoholics and control subjects. American Journal of Psychiatry 144, 854-859.

Schuckit, M.A., 1988. Reactions to alcohol in sons of alcoholics and controls. Alcoholism, Clinical and Experimental Research 12, 465-470.

Schuckit, M.A., Gold, E.O., 1988. A simultaneous evaluation of multiple markers of ethanol/placebo challenges in sons of alcoholics and controls. Archives of General Psychiatry 45, 211-216.

Schuckit, M.A., 1994. Low level of response to alcohol as a predictor of future alcoholism. American Journal of Psychiatry 151, 184-189.

Seale, T.W., Carney, J.M., 1991. Genetic determinants of susceptibility to the rewarding and other behavioral actions of cocaine. Journal of Addictive Diseases 10, 141-162.

Serrano, A., Parsons, L.H., 2011. Endocannabinoid influence in drug reinforcement, dependence and addiction-related behaviors. Pharmacology and Therapeutics 132, 215-241.

Shabani, S., et al., 2011. Sensitivity to rewarding or aversive effects of methamphetamine determines methamphetamine intake. Genes, Brain and Behavior 10, 625-636.

Shabani, S., et al., 2012a. A genetic animal model of differential sensitivity to methamphetamine reinforcement. Neuropharmacology 62, 2169-2177.

Shabani, S., et al., 2012b. Profound reduction in sensitivity to the aversive effects of methamphetamine in mice bred for high methamphetamine intake. Neuropharmacology $62,1134-1141$. 
Shen, E.H., et al., 1996. Correlated responses to selection in FAST and SLOW mice: effects of ethanol on ataxia, temperature, sedation, and withdrawal. Alcoholism, Clinical and Experimental Research 20,688-696.

Siu, E.C., et al., 2006. Nicotine self-administration in mice is associated with rates of nicotine inactivation by CYP2A5. Psychopharmacology 184, 401-408.

Sora, I., et al., 2001. $\mu$ opiate receptor gene dose effects on different morphine actions: evidence for differential in vivo $\mu$ receptor reserve. Neuropsychopharmacology 25, 41-54.

Spuhler, K., Deitrich, R.A., 1984. Correlative analysis of ethanol-related phenotypes in rat inbred strains. Alcoholism, Clinical and Experimental Research 8, 480-484.

Stephens, D.N., et al., 2011. The challenge of studying parallel behaviors in humans and animal models. Current Topics in Behavioral Neurosciences, http://dx.doi.org/10.1007/7854_2011_133.

Stern, K.N., et al., 1989. Reinforcing and subjective effects of caffeine in normal human volunteers. Psychopharmacology 98, 81-88.

Stolerman, I.P., et al., 1999. Discrimination and self-administration of nicotine by inbred strains of mice. Psychopharmacology 141, 297-306.

Sulem, P., et al., 2001. Sequence variants at CYP1A1-CYP1A2 and AHR associate with coffee consumption. Human Molecular Genetics 20, 2071-2077.

Sziraki, et al., 2001. Differences in nicotine-induced dopamine release and nicotine pharmacokinetics between Lewis and Fischer 344 rats. Neurochemical Research 26, 609-617.

Tagliabracci, C.E., Singh, S.M., 1996. Genetic regulation of gene-specific mRNA by ethanol in vivo and its possible role in ethanol preference in a cross with RI lines in mice. Biochemical Genetics 34, 219-238.

Tanda, G., et al., 2000. Self-administration behavior is maintained by the psychoactive ingredient of marijuana in squirrel monkeys. Nature Neuroscience 3, 1073-1074.

Tanda, G., Goldberg, S.R., 2003. Cannabinoids: reward, dependence, and underlying neurochemical mechanisms-a review of recent preclinical data. Psychopharmacology 169, 115-134.

Thiele, T.E., et al., 2000. High ethanol consumption and low sensitivity to ethanolinduced sedation in protein kinase A-mutant mice. Journal of Neuroscience 20, RC75.

Tritto, T., et al., 2002. Variability in response to nicotine in the LSxSS RI strains: potential role of polymorphisms in $\alpha_{4}$ and $\alpha_{6}$ nicotinic receptor genes. Pharmacogenetics 12, 197-208.

Tritto, T., et al., 2004. Null mutant analysis of responses to nicotine: deletion of $\beta_{2}$ nicotinic acetylcholine receptor subunit but not $\alpha_{7}$ subunit reduces sensitivity to nicotine-induced locomotor depression and hypothermia. Nicotine and Tobacco Research 6, 145-158.

Tuesta, L.M., et al., 2011. Recent advances in understanding nicotinic receptor signaling mechanisms that regulate drug self-administration behavior. Biochemical Pharmacology 82, 984-995.
Uhde, T.W., et al., 1984. Caffeine: relationship to human anxiety, plasma MHPG and cortisol. Psychopharmacology Bulletin 20, 426-430.

Varvel, S.A., et al., 2007. Lack of behavioral sensitization after repeated exposure to THC in mice and comparison to methamphetamine. Psychopharmacology 193, 511-519.

Volkow, N.D., et al., 1999. Reinforcing effects of psychostimulants in humans are associated with increases in brain dopamine and occupancy of $\mathrm{D}_{2}$ receptors. Journal of Pharmacology and Experimental Therapeutics 291, 409-415.

Wagner, F.A., Anthony, J.C., 2002. From first drug use to drug dependence; developmental periods of risk for dependence upon marijuana, cocaine, and alcohol. Neuropsychopharmacology 26, 479-488.

Waller, M.B., et al., 1986. Effect of low dose ethanol on spontaneous motor activity in alcohol-preferring and -nonpreferring lines of rats. Pharmacology Biochemistry and Behavior 24, 617-623.

Wheeler, J.M., et al., 2009. Genetically correlated effects of selective breeding fo high and low methamphetamine consumption. Genes, Brain and Behavior 8 , 758-771.

Whitfield, J.B., 2002. Alcohol dehydrogenase and alcohol dependence: variation in genotype-associated risk between populations. American Journal of Human Genetics 71, 1247-1250 (Author reply 1250-1241).

WHO, 1992. International statistical classification of diseases and related health problems 10th Revision (ICD-10). WHO, Geneva.

Wiley, J.L., et al., 2008. Age-dependent differences in sensitivity and sensitization to cannabinoids and 'club drugs' in male adolescent and adult rats. Addiction Biology 13, 277-286.

Yang, A., et al., 2010. Genetics of caffeine consumption and responses to caffeine. Psychopharmacology 211, 245-257.

Yang, J.N., et al., 2009. Physiological roles of $A_{1}$ and $A_{2 A}$ adenosine receptors in regulating heart rate, body temperature, and locomotion as revealed using knockout mice and caffeine. American Journal of Physiology. Heart and Circulatory Physiology 296, H1141-H1149.

York, J.L., 1981. The ethanol stimulus in rats with differing ethanol preferences Psychopharmacology 74, 339-343.

Zacny, J.P., et al., 1992. Subjective and behavioral responses to intravenous fentanyl in healthy volunteers. Psychopharmacology 107, 319-326.

Zacny, J.P., et al., 1994. A dose-response analysis of the subjective, psychomotor and physiological effects of intravenous morphine in healthy volunteers. Journal of Pharmacology and Experimental Therapeutics 268, 1-9.

Zacny, J.P., Gutierrez, S., 2003. Characterizing the subjective, psychomotor, and physiological effects of oral oxycodone in non-drug-abusing volunteers. Psychopharmacology 170, 242-254. 